\title{
University Performance Evaluation: The Business Of Research
}

Brenda Ridgewell, (Email: B.Ridgewell@ exchange.curtin.edu.au), Curtin University of Technology, Australia Greg Tower, (E-mail: greg.tower@ cbs.curtin.edu.au), Curtin University of Technology, Australia

\begin{abstract}
The study examines the impact of national research assessment exercises for the visual arts discipline in a university structure. It encompasses issues of evaluation, benchmarking, performance management, performance indicators and explanatory factors. We find that whilst the definition of research is broad enough to include most of the activities of visual arts academia. The actual operationalisation of the measurement models may well exclude many current activities. The need to clearly demonstrate quality peer review is the largest hurdle. Analysis is also made of the impact of a 'national research quality assessment exercise' such as the New Zealand and UK initiatives (Tertiary Education Commission. 2004; RAE, 2001). Whilst visual arts academia research performance activity was ranked low in both countries, we find that their position on the need for quality and peer assessment offers a potentially broader and more accurate depiction of activity. Obtaining a balanced broader assessment of both traditional performance measures such as research publications along with the more creative elements of visual arts such as exhibitions is paramount.
\end{abstract}

The national assessment exercises show that visual arts academics are struggling to compete with their academic brethren in other disciplines. We argue the need for national assessment exercises engenders an acceptable peer review system to better assess their broad research activities for non-traditional areas. We also make calls for more research presentation training for the visual arts discipline to assist them in the recognition of quality research productivity. The implementation of a national research assessment system which focuses more on quality output and outcome measures instead of input measures such as research income will engender this debate.

\section{INTRODUCTION}

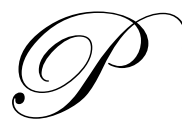

by the selected performance indicators." robably the main reason for introducing a performance-based approach to the funding of university research is the belief that it is meritocratic, proving a reward for those with a record of successful research, and thus constituting a strong incentive for improving the quality of research as measured

The visual arts are an important and very large global industry. A Picasso painting has been sold for over \$104 million, The British Crown Jewels and Da Vinci's Mona Lisa are considered invaluable or even priceless. Auction houses such as Sotheby and Christies are multimillion dollar businesses (http://news.bbc.co.uk/ 2/hi/uk_news/magazine/3689967.stm). In many ways a civilisation is judged by its artistic contributions (McNeil, 1979; Diamond, 1997). The higher education sector plays a vital role in this artistic contribution (Ross, 2004). The study is specifically focused on critiquing the likely impact of various research performance assessment exercises upon academics in the visual arts discipline. It encompasses issues of benchmarking, performance indicators and performance management.

The paper is organised as follows. Section 2 critically examines the definition of research and highlights the unique problems of measuring and rewarding non-traditional research activities in visual arts academia such as 
exhibitions. Section 3 critiques the strengths and weaknesses of and various country-based research assessment exercises and links it to the visual arts discipline. Section 4 concludes the paper by outlining the implications of the findings and reflecting on the likely impact of a research assessment exercise in a country such as Australia.

\section{REFLECTIONS ON RESEARCH CRITERIA}

\section{Assessing Research}

Research activities are an essential contribution by universities. Governments, as the biggest funding resource for universities, expect value for money. Often performance indicators are used and published to demonstrate an entity's (or discipline's) activity concerning efficiency and effectiveness. These terms are defined as cost-savings and cost-controls; and the benefit of the research as compared to the cost to produce it, respectively. A university's research performance can also be measure in terms of inputs, outputs and outcomes:

- $\quad$ An important input is external research income received.

- $\quad$ Research publications such as journal articles and scholarly books are the key research outputs.

- $\quad$ Research outcomes, such as the improvement of a society's living standards are much harder to measure.

- Arguably an input is less important as it is a measure of efficiency whereas effectiveness such as outputs and outcomes are vital.

In academia there are different country models. Australia largely funds research on inputs (RQF, 2005) and countries such as the UK and New Zealand are now putting far more effort into measuring outputs (Tertiary Education Commission, 2004). Measuring outcomes is part of these latter countries criteria via peer assessment of their contribution to society (see the British RAE, 2001 as an excellent example). In other words they use a surrogate value for research outcomes by seeking to measure the quality of the research outputs.

For instance, the UK Research Assessment Exercise Panel on Art and Design states "In assessing the quality of research outputs, the Panel will assess the significance to the relevant discipline. In so doing, the panel will refer to evidence of the following whenever appropriate: level of innovation; contribution to knowledge; appropriateness of publisher, sponsor or commissioning body/client, venues, locations; appropriateness of means of dissemination; level frequency of circulation of dissemination and accessibility to future generations; quality of associated media, documentation, catalogue or reviews; translations made; citation in press or year books, source of funding or sponsorship; scale of competition; prizes or awards received" (paragraph 3.55.15 www.hero.ac.uk/rae/criteria/ crit64.htm accessed 24/03/2005).

The British RAE criteria for Art and Design quoted above has a mixture of content measures, context, external validation and some references to outcomes:

- $\quad$ Content criteria include level of innovation and quality.

- $\quad$ Context examples are frequency of circulation and scale of competition.

- $\quad$ The outcome criteria such as level of contribution and accessibility to future generations are arguably important and worthy of consideration but difficult to measure.

All the above seek to focus on the quality and importance of the research. Thus, the definition of research is paramount (Lucas, 2004). The level of exclusivity, especially for a non-traditional academic field such as the practice-based research of visual arts, is crucial to accurately measure academic research performance.

We define practice-based as the recognition of the creative output focus such as the development of creative works for exhibit, such as the making of jewellery for show. We argue that visual art academics are now expected to disseminate to major categories of research output: 1) practice-based works for exhibit and 2) scholarly writings in refereed journals. 
Especially problematic is the need for visual arts academics to be able to demonstrate their contribution in the scholarly/theory domain as well as the practice of production of artworks. Key questions thus arise. What is included in the definition? What activities are excluded? How does this affect less-traditional academic disciplines such as visual arts?

\section{Defining Research}

The Oxford English Dictionary Online (http://dictionary.oed.com.ezproxy.library.uwa.edu.au/entrance.dtl, 2005) dictionary defines research as both a noun "Investigation or pursuit of a subject" and as a verb "To search into (a matter or subject); to investigate or study closely." (http://dictionary.oed.com.ezproxy.library.uwa.edu.au/ cgi/findword?query_type $=$ word\&queryword=research\&find. $\mathrm{x}=41 \&$ find. $y=11$ ).

As a broad definition this can be applied to the Visual Arts. Provided the assessor of the research output is thinking laterally about the nature of research, this section of the definition could also allow the visual arts a placement within this framework.

The British Research Assessment Exercise provides a more detailed definition of research:

'Research' is to be understood as original investigation undertaken in order to gain knowledge and understanding. It includes work of direct relevance to the needs of commerce and industry, as well as to the public and voluntary sectors; scholarship; the invention and generation of ideas, images, performances and artefacts including design, where these lead to new or substantially improved insights; and the use of existing knowledge in experimental development to produce new or substantially improved materials, devices, products and processes, including design and construction ${ }^{1}$. (http://195.194.167.103/Pubs/other/raeguide.pdf, 2005).

The British RAE definition of research allows for a practice based investigation/research to be recognised. Provided the recognition of a practice based research is upheld within the assessment it could be argued that this would be an adequate definition to assess visual arts research.

The New Zealand research assessment exercise has a definition that more clearly deals with the creative side of research. They state:

Research is original investigation undertaken in order to gain knowledge and understanding. It typically involves enquiry of an experimental or critical nature driven by hypotheses or intellectual positions capable of rigorous assessment. It is an independent, creative, cumulative and often long-term activity conducted by people with specialist knowledge about the theories, methods and information concerning their field of enquiry. (Note: The term 'independent' here should not be construed so as to exclude collaborative work.) Its findings must be open to scrutiny and formal evaluation by others in the field, and this may be achieved through publication or public presentation. In some fields, the results of the investigation may be embodied in the form of an artistic work, design or performance. Research includes contribution to the intellectual infrastructure of subjects and disciplines (e.g. dictionaries and scholarly editions). It also includes ${ }^{2}$ the experimental development of design or construction solutions, as well as investigation that leads to new or substantially improved materials, devices, products or processes. (http://www.otago.ac.nz/research/pbrf/\#definition, 2005).

Arguably, this definition directly lists artistic work as a research/ investigation process. This provides a starting point for recognition that the other definitions excluded or hide under the umbrella of design, construction or things.

\footnotetext{
${ }^{1}$ The British RAE goes on to state: "It excludes routine testing and analysis of materials, components and processes, eg for the maintenance of national standards, as distinct from the development of new analytical techniques. It also excludes the development of teaching materials that do not embody original research."

${ }^{2}$ The New Zealand PBRF excludes traditional items including "Any other routine professional practice (e.g. in arts, law, architecture or business)".
} 
The Australian federal government agency Department of Education, Science and Training (DEST) uses the OECD definition of research which comprises:

Creative work undertaken on a systematic basis in order to increase the stock of knowledge, including knowledge of man, culture and society, and the use of this stock of knowledge to devise new applications. Any activity classified as research is characterised by originality; it should have investigation as a primary objective and should have the potential to produce results that are sufficiently general for humanity's stock of knowledge (theoretical and/or practical) to be recognisably increased. Most higher education research work would qualify as research. (http://www.dest.gov.au/highered/research/documents/specs2005.pdf, 2005).

The proposed new definition, recommended by the RQF (2005, Part 1) is a shorter variant of the OECD definition simply stating, "creative work undertaken on a systematic basis in order to increase the stock of knowledge. Upon reflection, the breadth of the OECD definition is all encompassing; however, the shorter version appears to limit more creative elements such as those found in the performing arts. Moreover, a key ingredient, the method of assessment of research is not defined.

Hong Kong adopted a similar policy and approach to the UK RAE. However, it is worth noting that the outputs used for assessment in the Hong Kong RAE are sufficiently loosely defined to allow for more varied measures than those that support standard academic research excellence such as publications (RQF, 2005). "This broader definition of an output also allows for creative performance, exhibitions and other items to be nominated for assessment so long as they are 'publicly accessible' through video, photographs, or some other submittable format (RQF, 2005, Appendix C).

Lucas (2004) notes that the HK RAE widened the definition of research with the intention to allow for more creative and innovative research activity. The Carnegie (1990) definition, used by the HK RAE focuses on the broader concept of 'scholarship' which they argue encompasses: discovery; the scholarship of integration; the scholarship of application; and the scholarship of teaching (see Appendix A for the full definition). In effect it looks broader by considering a wider arrange of societal needs such as passion, interpretation, dynamism and extension. This broader definition of output also allows for creative performance, exhibitions and other items to be nominated for assessment so long as they are publicly accessible through video photographs or some other submittable format (RQF, 2005).

As all these above definitions are broadly worded and aimed to provide placement for all research, the manner in which the level of research and therefore the recognition of the research is determined is probably more important to the researcher than the definition. For instance, Lucas (2004, p.7) states "It seemed that for both the individual involved in RAE submission and for the RAE panel members the criteria for evaluating the scholarship of discovery or the traditional basic research category was perceived to more straightforward ..." [it] "not only more apparent in terms of how it can be evaluated but that it ultimately carries more prestige than other forms of scholarship."

How research is assessed across disciplines from the traditional written paper to the practice based research of contemporary universities is of major angst for practice based researchers. Having practice based research rewarded in an equitable complementary manner to the traditional written paper is providing an obstacle for universities throughout Australia. Therefore, the next section provides a critique of various research assessment models and the actual ratings of visual art academics.

\section{CRITIQUE OF DIFFERENT ASSESSMENT MODELS}

The OECD (1987, p.19) notes the mounting level of concern about "the increasing cost of funding university-based research". RQF (2005) argues there are three main models for national-based assessment exercises. The first are models not directly linked with research funding (eg continental European countries such as Germany). The second model focuses on outcomes driven block funding for research (eg UK and HK). The final model mixes elements of both (eg New Zealand). 


\section{Divergent Assessment Model: No Direct Links To Research Funding}

Many countries in continental Europe use the first model. In Germany, no research performance measures are used to allocate research funds and there has been no evaluation for this purpose. However, there have been several evaluation of university research these have not influenced funding. The Australian federal government is now beginning to stress the increasing need for research evaluation (RQF, 2005).

The Netherlands' research evaluation system has several purposes none of which are directly related to funding (Lucas, 2004). The end result of the assessment process is a ranking which helps to underpin an institution's reputation or claims for research excellence (Geuna \& Martin, 2003). While there have been no research evaluations for the purpose of allocating funds there have been evaluations for strategy formation. Unlike the RAE where disciplines are evaluated simultaneously, they are evaluated at different times over a six year period. Committees assess each research programme in terms of four aspects: scientific quality, scientific productivity, scientific relevance and long-term viability. Therefore, this approach takes into account both quantity and quality. Guena and Martin (2003) argue there are strong advantages to the Dutch system. They feel it has a better cost-benefit ratio in that quality of research is assessed therein enhancing research resource decisions whilst still keeping the costs to a minimum.

The Italian system has some similarities to the current Australian system, The Minister of Universities and Scientific and Technological Research (MURST) provide basic institutional funding, which includes a small portion for non-directed research and also allocates funds for individual research project through grants distributed on a competitive basis. Core funding is allocated to each university according to number of teaching and research staff, while funding for targeted research is allocated through peer review of application. However, with the exception of peer review of application there has so far been no specific evaluation of university research related to the funding allocations. Finland and Denmark (again similar to Australia) also have a performance-based component using quantitative indicators such as the amount of external funding (Geuna \& Martin, 2003).

For instance, the Finnish Ministry for Education has suggested creating a performance-based funding mechanism similar to the RAE in the UK. The ministry had a report which suggested that $35 \%$ of operational funds should be allocated on the basis of research performance evaluated by the academy of Finland every three years using peer review and funds would be allocated accordingly. This proposal was criticized by almost every university and was not pursued by the ministry. The main objections include undue influence over policy and it would result in a normative standard for resource allocation among universities (Kaukonen, 1997). Overall, there appears to be a growing call for some sort of research assessment exercise. Several continental European countries are considering linking research to performance and funding more directly (Geuna \& Martin, 2003). Concerns about the loss of independence of the universities and the cost of such exercises are the main hurdles.

\section{Linked Model: Funding Tied To Research Assessment}

The second model directly links research funding to an assessment of research. The United Kingdom and Hong Kong exercises are two acknowledged examples.

Clear advantages of the British-style RAE are that it has provided the basis for increased research funding and more comprehensive information on the quality of research being undertaken. Disadvantages include the concern for the financial sustainability of research in some disciplines, inequitable workplace behaviours, administrative burden and costs, and a need to fully recognize all aspects of excellence in research (RQF, 2005). The UK experience has shown that including operational costs, and RAE amounts to less than $1 \%$ of the funds allocated on the basis of the exercise. 
Table 1: National Research Assessment Exercises

\begin{tabular}{|c|c|c|}
\hline Overview & Disadvantages & Advantages \\
\hline $\begin{array}{l}\text { - Most countries examined have } \\
\text { either recently implemented some } \\
\text { form of performance-based } \\
\text { allocation or are considering doing } \\
\text { so } \\
\text { Current practice in university } \\
\text { research evaluation and funding is } \\
\text { the result of policy pressures for } \\
\text { greater accountability for research } \\
\text { funding } \\
\text { The UK is usually considered to be } \\
\text { leading this trend. } \\
\text { In many cases, the academic } \\
\text { community has resisted the } \\
\text { introduction of specific evaluation } \\
\text { criteria for university research } \\
\text { output or at least the linking of } \\
\text { evaluation results directly to } \\
\text { research funding decisions } \\
\text { At present we lack the detailed data } \\
\text { on university research inputs and } \\
\text { outputs over a long period of time } \\
\text { needed to identify with confidence } \\
\text { the results of different resource } \\
\text { allocation systems } \\
\text { Main reason for implementing a } \\
\text { performance-based approach is the } \\
\text { belief it is meritocratic, providing a } \\
\text { reward for those with a record of } \\
\text { successful research and thus } \\
\text { constituting a strong incentive for } \\
\text { improving the quality of research } \\
\text { Performance based system can } \\
\text { identify where resources have } \\
\text { previously been spent on } \\
\text { departments that have been less } \\
\text { successful and can shift resources } \\
\text { to where they will be used with } \\
\text { greater effect. } \\
\text { strategies than prior methods } \\
\text { - }\end{array}$ & 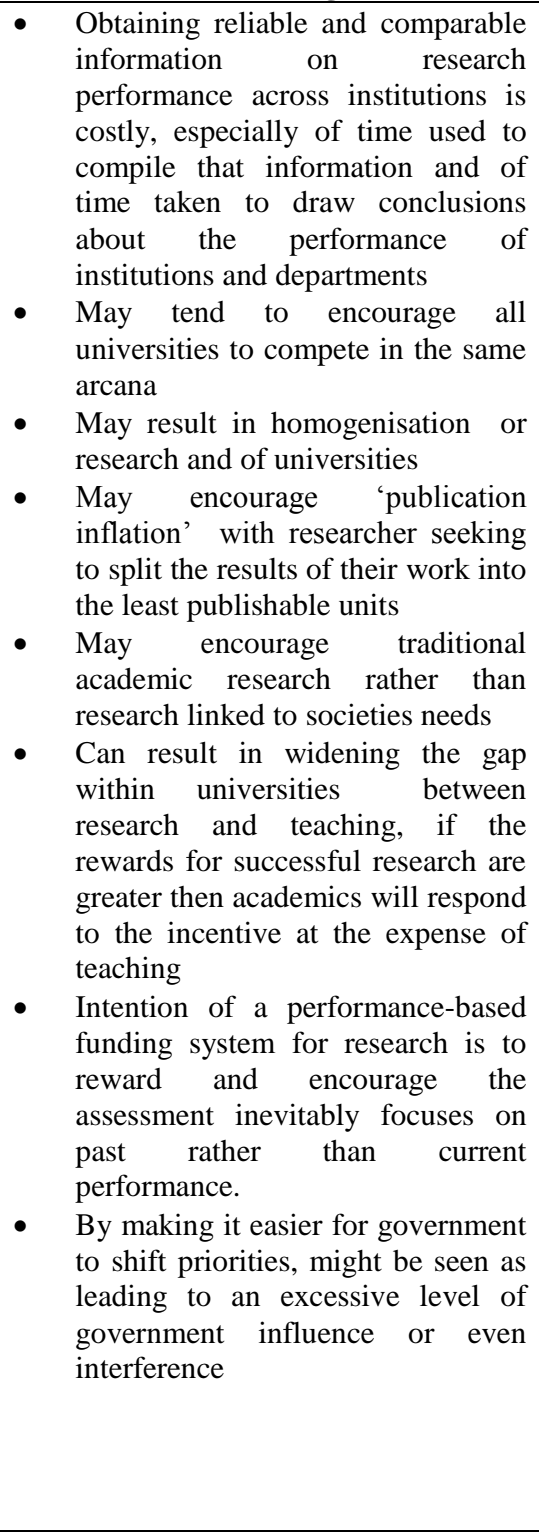 & $\begin{array}{l}\text { - Meritocratic in that it links } \\
\text { research to performance, ie may } \\
\text { reward good research } \\
\text { - It provides institutions and } \\
\text { departments with 'seed corn' funds } \\
\text { to invest in new or younger } \\
\text { members of staff or in new areas } \\
\text { Competition may lead to increased } \\
\text { efficiency, ie ineffective research } \\
\text { may be identified and cut } \\
\text { Encourages research to be properly } \\
\text { completed and written up for wider } \\
\text { dissemination } \\
\text { Encourages more explicit research } \\
\text { strategies } \\
\text { May be more likely to try different } \\
\text { approaches and to work on more } \\
\text { speculative areas } \\
\text { Provides a mechanism for linking } \\
\text { university research to government } \\
\text { policy } \\
\text { Concentration of resources may } \\
\text { enable department to compete with } \\
\text { world leaders }\end{array}$ \\
\hline
\end{tabular}

Sources: RQF, 2005; Tertiary Education Commission, 2004, British RAE, 2001; Geuna \& Martin, 2001.

Hills and Dale (1995) argue that the UK RAE is one of the most advanced systems in Europe. Evaluation not just based on the individual researcher or project, but also at institutional and national level. The RAE is an ex post evaluation based on informed peer review. All research activities are categorised into a number of units of assessment. Chairs and panel members are based on factors such as eminence of individuals, convergence of the subject, and sectoral and geographical balance. There have been five British assessment exercises (1983, 1986, 1991, 1999, and 2001 with another one forthcoming in 2008). In 1996 the RAE changed to only require four publications by each researcher, as to reduce the problem of the low quality rush publications as a result of pressure within the department to produce as many publications as possible to increase the total aggregate. On the basis of all the information, panel 
assigned a rating of 1 to 5 . The funding bodies used the rating in the formula ${ }^{3}$ applied to determine the research the funding for each unit of assessment, with the total block grant received being calculated by summing across all units (RQF, 2005). Informal and formal league tables use the data to rank UK universities (see for instance the Education Guardian (2005) 'RAE Tables'.

Hong Kong adopted a similar system to the UK and has had three assessment exercises (1991, 1996, and 1999 with another one forthcoming in 2006). Visual arts (labelled 'arts') was one of the 58 'cost centres' used to categorise $\mathrm{e}^{4}$ the academic disciplines. The Research Grants Council (RGC) which operates under the UGC allocates research project grant based on rigorous peer review involving international experts in order to concentrate funds on high quality research (Geuna \& Martin, 2003). There are some key differences between the UK and HK RAE. In Hong Kong, the focus is on the individual and outputs (such as publications) are "... judged purely on whether they pass the 'threshold' standard and if so they are awarded a 1 grade. The number of 1 grade ratings within a cost centre is then used to determine the level of funding to be given. As a result of this, all individual within academic departments are required to be research active and to perform well enough in their research output to pass the threshold standard" (Jones, 2004, p.6). Van der Zahn (2005) notes that the HK exercise was a drive to streamline university course and research to central areas and a realisation that universities were costing a lot of money and there was a need for realignment.

\section{Mixed $^{5}$ Model}

The most recent national assessment exercise was conducted by New Zealand in 2003. Table 2 reviews the key elements and adds a comparative commentary column which compares this to the British approach and reviews strengths and weaknesses. As shown in Table 2 the New Zealand PBRF is a mixed model of assessment. Most of the university funding is still based on student numbers yet a small amount of monies (NZ 18 million) was allocated based on research performance using the PBRF criteria. The governmental funds linked to performance are anticipated to rise dramatically. We analyse the overall structure of such an approach and the likely impact on the visual arts discipline. The key points in regards to its structure are:

- $\quad$ NZ PBRF provides an example of a more recently established research assessment process in which the individual researcher is the focal point for assessment. Unlike the UK RAE, but similar to earlier Hong Kong RAE the NZ PBRF involves the direct assessment of all individual academic staff rather than academic units. This could disadvantage 'young' disciplines such as visual arts, however, it would allow for a more complete picture of the current state of play of the entire discipline.

- $\quad$ The PBRF is a mechanism for distributing funding as well as existing funding on the basis of the highest quality researchers. Visual arts may be a net loser out of such a structure.

- $\quad$ The NZ PBRF is differentiated from pervious models by a clearly stated funding formula that combines peer review with performance indicator measures. The peer review component arguably allows for visual arts academics to be judged by their peers on discipline-appropriate criteria.

- The formula allocates $60 \%$ for peer review assessment, $25 \%$ for research degree completions and $15 \%$ for external research income earnings. The emphasis on peer assessment judged outputs arguably is fairer than a research income biased approach. (RQF, 2005, Tertiary Education Commission, 2004).

\footnotetext{
${ }^{3}$ Harnad, Carr, Brody and Oppenheim (2003) advocate that national assessment exercises make greater use of citations as measured by Journal Impact Factors (JIF) which is that average number of citations per article per year. They argue there is a high correlation (above .8) of the JIF with the science-based discipline UK assessments.

${ }^{4}$ The categorisation of disciplines differed for the three main national assessment exercises. Hong Kong treated (visual) arts separately thus allowing for more focused analysis. The New Zealand PBRF grouped 'creative and performing' arts together. We feel that both groups have very similar characteristics therefore comparisons are not diminished. In contrast, the British RAE lumped 'art' and 'design' together. We feel that this deflates the performance ratings of the 'art' group but are unable to exactly measure the level of reduction.

${ }^{5}$ An example of a different 'mixed model' for research and quality assessment and incentive funding is Ireland's Program for research in Third Level Institutions (PRTLI). The PRTLI model focus is more about making a research funding investment on the basis of quality than ranking institutions. .Each proposal is scored on three criteria, strategic planning (40\%), research quality (35\%) and teaching $(25 \%)$ in later rounds strategic planning was split to allow $10 \%$ for inter-institutional collaboration.
} 
Table 2: Key Components Of The NZ Performance-Based Research Fund Assessment Exercise (2003)

The PBRF set of principles
- Comprehensiveness, Respect for academic traditions,
Consistency, Continuity, Differentiation, Credibility,
Efficiency, Transparency, Complementarily, and
Cultural inclusiveness.

Unit of Evaluation

- The quality evaluation involves the direct assessment of individual staff rather than academic unit.

Evidence portfolios and the assessment framework

- The research component is comprised of up to four 'nominated research outputs' as well as up to 50 percent of 'other research outputs'. The research component had a $70 \%$. The peer esteem component is comprised of the recognition of a staff members' research by his peers and has $15 \%$ weighting.

- The contribution to research environment component comprises a staff member's contribution to a vital highquality research environment and has a $15 \%$ weighting (including both research income and postgraduate research supervision).

Nominated Research output by type

- Artefact/object, Film/video, Software, Design output, Exhibition, Performance, Authored book, Chapter in book, Conference contribution, Journal Article

Participation in the PBRF

- $\quad$ For the 2003 quality evaluation, there were four Quality Categories (A, B, C, R).

- In all cases the panels employed the following methods: 1) Each evidence portfolio was assembled by a pair of panel members. 2) Panel devoted considerable attention to the determination of final scores for the three components of evidence portfolios (ie research output, peer esteem and contribution to research environment).

Scope of the nation wide assessment exercise

- Of the 8013 PRBF eligible staff participating TEOs, 5771 had their evidence portfolios assessed by a peer review panel.

Source: Tertiary Education Commission, 2004

\section{Commentary}

- These statements would be generally acceptable to all although cultural inclusiveness would be hard to incorporate. The credibility criterion is an ongoing problem for Visual Arts needing to constantly ensure their research is assessed equivalently to the journal reviewing method.

- This is unlike the research assessment exercise (RAE) In Britain, but in keeping with the Hong-Kong RAE.

- This weighting is very similar to the British RAE. However, these greatly differ from the present Australian system that assigns only $10 \%$ to publications, $0 \%$ to peer esteem, $60 \%$ to grants and $30 \%$ to postgraduate research student completions.
- This broad list is inclusive of the key Visual Arts performance categories.
- The British and HK RAE also uses the peer review approach, whereas most continental European countries tend to fund based on student number or have much smaller research assessment approaches Geuna \& Martin, 2001).

- The peer review approach may well validate less traditional visual art academics' output such as performances and exhibitions.

- The British RAE had a fundamentally different scope by allowing universities to put forth those academics they deemed worthy. However, Hart (2005) argues the result was the percentage staff participating was ignored whilst the overall ranking was considered paramount. Therefore, the British RAE unlike the NZ PBRF did not assess the entire population.

Tertiary Education Commission (2004) felt its initial 2003 assessment exercise was very successful. It states it is confident that the results of the 2003 quality evaluation provide an impetus for tertiary bodies to review their research plans and strategies. TEC (2004) recognised that the funding received by certain entities through the PBRF in 2004 may fall short of the costs of participation. Interestingly, they also acknowledge that many New Zealand academics are likely to feel that their research efforts have not been properly recognized. In this context the TEC is aware that aspects of the PBRF remain controversial within the tertiary education sector. 
This paper reflects on the impact of such exercises on actual performance ratings of visual arts academics. Accordingly, the next sub-section details this disciplines ratings in the most recent New Zealand and British research assessment exercises.

\section{Reflections On Visual Arts Research Performance Rankings}

Tables 3-5 highlight the performance ranking of visual art academics in the New Zealand and British research assessment exercises.

Overall, the Visual Arts discipline fair poorly in these national rating by discipline. Table 3 shows that the New Zealand assessment used a very stringent and arguably harsh set of criteria. The best ranked university received less than a four score out of a ten point scale. Plummer (2005) argues that this scale was greatly demeaning to New Zealand academics in that far too many academics and disciplines were given very low ratings. The visual arts were ranked 37 of the 41 disciplines. They had an overall score of less than two of a ten point scale. Table 3 also highlights that individual academics were considered lower than average across the board with smaller percentages of the two highest categories (A and B) and more in the lowest ' $\mathrm{R}$ '" category.

Table 4 illustrates the 2001 overall British RAE results and the specific 'Arts and Design' discipline. In stark contrast to the NZ scale, the British RAE had a healthy $39 \%$ of all universities ranked in the highest 5 or $5^{*}$ categories. Yet, the 'Art and Design' discipline faired less well with only 16\% in these elite categories. The 1996 results show a similar trend albeit with lower elite scores in both the overall results and the 'Art and Design' discipline. The individual findings shown in Table 5 are consistent with the discipline findings. Whereas $36 \%$ and $19 \%$ of British academics were given the highest two ratings in the 2001 exercise, the equivalent scores for British 'Art and Design' academics were much lower at 0\% and 22\% respectively (with 1996 again showing similar albeit lower scores). The differences could be a result of: 1) improved performance of all British academics as they realise the growing importance of quality research over time, or 2) they better learn how the system works and use gaming strategies (such as level of unit to be assessed at) to maximise their results, or 3) the UK academics may well system grade higher than their Australasian brethren.

There are several reasons for the lower ratings for visual arts academics:

- $\quad$ There are lower levels of scholarly research training with art academics having one of the lowest levels of doctoral training for academics (in Australia it is below 40\%). Within the visual arts until the mid 1990s the level of educational achievement in countries such as Australia and New Zealand was a BA, then the MA by research and course work were embraced as most other disciplines were moving to gain PhDs, only recently has the $\mathrm{PhD}$ qualification and the respected echelon of research attained at that stage of academia been embraced by the visual arts academia.

- $\quad$ Higher teaching loads Visual Arts staff receive teaching and research appointments. There are no research only staff in most universities. Recognised mentors for theoretical research are very generous in helping new researchers in the field, but the challenge for most practice based researchers is to find the time away from practice to write.

- $\quad$ Lower availability of grants: There are lower amounts available for social science research and the lower scholarly refereed journal track record output by visual art academics makes it more difficult to compete against other more established science or social science disciplines. As visual art staff has throughout time had difficulty in gaining recognition for their research output, there is also very little monies available for research assistance to develop to the level of research produced in other areas of academia.

- More individualistic nature of visual art research outputs: Often university research output is greatly magnified by research groups such as large science-based laboratories. In the visual arts groups of researchers are rarer, the individual time consuming nature of practice based research produces far less output and hence less recognition at assessment exercises. The visual arts practice based research is very ego-centric personal research, based in research methods that often exclude mentoring, or obscurity eludes others input other than aesthetically so the level of mentoring is often not measurable. 
Table 3: Visual Art Research Performance In New Zealand

\begin{abstract}
The results of the 2003 Quality Evaluation
- $\quad$ Under the approach adopted, the maximum quality score that can be achieved by a TEO (subject area or nominated academic unit) is 10 . In order to obtain such a score, however, all the PBRF-eligible staff in the relevant TEO would have to receive an 'A' Quality Category. With the exception of very small academic units such an outcome is extremely unlikely. No sizeable academic unit, et alone a large TEO, could reasonably be expected to secure quality score even close to 10.

- $\quad$ The low quality score reflects the very large numbers of staff whose evidence portfolios were assigned an " $R$ ".
\end{abstract}

Key Findings

- The overall FTE-weighted quality score for the 22 participating TEOs is 2.6 out of a potential 10

- $\quad$ A relatively high proportion of the PBRF-eligible staff $(39.9 \%$ FTE weighted) were deemed to not yet meet the standard requires for achieving a $\mathrm{C}$ Quality category and were assigned an R.

- $\quad 31.7 \%$ PBRF-eligible staff (FTE weighted) in the university sector were assigned to an A or B Quality Category.

- $\quad$ There are marked differences in the research performance of the 41 subject areas. While some subject areas have a substantial proportion of researchers in the A and B Quality categories, others have had hardly any. Altogether 11 of the 41 subject areas have a quality range of less than 2.0 and thus an average sore within the $\mathrm{R}$ range (0 to 1.99$)$. In general the best results were achieved by long-established disciplines with strong research cultures such as philosophy, chemistry and psychology. Relatively high quality scores were achieved by subject areas within the biological and physical sciences, the humanities and the social sciences. Many subject areas with low quality scores are newer disciplines such as design; nursing; sport; exercise science, theatre, dance, film and television and multimedia. Against this with only a few exceptions, subject areas in the fields of business and the creative and performing arts had below-average quality scores.

Visual Arts Performance

- $\quad$ FTE-weighted quality scores

- Creative and Performing Arts 1.99 (Figure A-2); overall average for all disciplines was 2.59

Table A-44 Results (weighted FTE basis by subject area- Visual Arts and Crafts:

- $\quad$ Staff Rated A: 3.2\% (overall average for all disciplines= $5.7 \%$ )

- $\quad$ Staff Rated B: $19.6 \%$ (overall average was 23.2\%)

- $\quad$ Staff Rated C: $36.4 \%$ (overall average was $31.2 \%$ )

- $\quad$ Staff Rated R: $40.8 \%$ (overall average was $39.9 \%$ )
- A major weakness of the New Zealand PBRF is the harshness of the scale applied. The highest university (Auckland) received only an aggregate 3.96 score out of ten. This is a low rating that makes it very hard to 'market' their strengths internationally. In contrast the UK RAE ranked $39 \%$ a 5 or $5^{*}$ out of a $0-5^{*}$ scale allowing for wide-scaled overseas advertising for their high ranked universities. Zealand academics (Van Peursem, 2004).

- The New Zealand PBRF used a uniform expectation within a peer panel, therefore early career researchers were ranked downwards ${ }^{6}$. This approach is arguably very inequitably and encourages departments into short term strategies (hire the top guns now) versus more long-range planning (acquire and grow talented early career researchers).

- As discussed in the following section it is an open question whether these major differences are a result of a flawed process or fundamental differences between disciplines.

\footnotetext{
${ }^{6}$ The New Zealand PBRF (2004) acknowledged the problem in their report in stating "it is important to stress that there is a large proportion of new and merging researchers, many of high calibre and potential among these Rs".
}

As stated above, the Visual Arts was ranked 37 of 41 academic disciplines in the New Zealand PBRF. The average score of 1.99 just fell into the bottom ' $R$ ' category.

- Visual arts academics had lower scores in the top two categories. Interestingly, their percentage of staff in the non-active research category ('R') was only slightly lower than the average of all other disciplines. 
Table 4: Visual Art Research Performance In The U.K. Compared To The Overall Results Of Performance

\begin{tabular}{ccccccccc}
\hline Grade & $\begin{array}{c}2001 \\
\text { Overall } \\
\text { Results }\end{array}$ & $\begin{array}{c}2001 \\
\text { Overall } \\
\text { Results } \\
(\%)\end{array}$ & $\begin{array}{c}2001 \text { Art } \\
\text { and } \\
\text { Design } \\
\text { Results }\end{array}$ & $\begin{array}{c}2001 \text { Art } \\
\text { and } \\
\text { Design } \\
\text { Results } \\
(\%)\end{array}$ & $\begin{array}{c}1996 \\
\text { Overall } \\
\text { Results }\end{array}$ & $\begin{array}{c}1996 \\
\text { Overall } \\
\text { Results } \\
(\%)\end{array}$ & $\begin{array}{c}1996 \text { Art } \\
\text { and } \\
\text { Design } \\
\text { Results }\end{array}$ & $\begin{array}{c}1996 \text { Art } \\
\text { and } \\
\text { Design } \\
\text { Results } \\
(\%)\end{array}$ \\
\hline 1 & 18 & 1 & 1 & 1.33 & 236 & 8 & 12 & 13.48 \\
2 & 140 & 5 & 5 & 6.67 & 464 & 16 & 14 & 15.73 \\
$3 \mathrm{~b}$ & 278 & 11 & 11 & 14.67 & 422 & 15 & 20 & 22.47 \\
$3 \mathrm{a}$ & 499 & 19 & 25 & 33.33 & 528 & 18 & 25 & 28.09 \\
4 & 664 & 26 & 21 & 28 & 671 & 23 & 11 & 12.36 \\
5 & 715 & 28 & 12 & 16 & 403 & 14 & 4 & 4.49 \\
$5 *$ & 284 & 11 & 0 & 0 & 170 & 6 & 3 & 3.37 \\
Total & 2598 & 100 & 75 & 100 & 2894 & 100 & 89 & 100 \\
\hline
\end{tabular}

Table 5:

Visual Art Category A And A* Research Active Staff (FTE) In The U.K. Compared To The Overall Category A And A* Research Active Staff (FTE)

\begin{tabular}{|c|c|c|c|c|c|c|c|c|}
\hline Grade & $\begin{array}{c}2001 \\
\text { Overall } \\
\text { Category } \\
\text { A and A* } \\
\text { Staff } \\
\text { (FTE) }\end{array}$ & $\begin{array}{c}2001 \\
\text { Overall } \\
\text { Category } \\
\text { A and A* } \\
\text { Staff } \\
(\text { FTE) }(\%)\end{array}$ & $\begin{array}{l}2001 \text { Art } \\
\text { and } \\
\text { Design } \\
\text { Category } \\
\text { A and A* } \\
\text { Staff } \\
\text { (FTE) }\end{array}$ & $\begin{array}{l}2001 \text { Art } \\
\text { and } \\
\text { Design } \\
\text { Category } \\
\text { A and A* } \\
\text { Staff } \\
\text { (FTE) }(\%)\end{array}$ & $\begin{array}{c}1996 \\
\text { Overall } \\
\text { Category } \\
\text { A and A* } \\
\text { Staff } \\
\text { (FTE) }\end{array}$ & $\begin{array}{c}1996 \\
\text { Overall } \\
\text { Category } \\
\text { A and A* } \\
\text { Staff } \\
(\text { FTE) } \\
(\%)\end{array}$ & $\begin{array}{l}1996 \text { Art } \\
\text { and } \\
\text { Design } \\
\text { Category } \\
\text { A and A* } \\
\text { Staff } \\
\text { (FTE) }\end{array}$ & $\begin{array}{l}1996 \text { Art } \\
\text { and } \\
\text { Design } \\
\text { Category } \\
\text { A and A* } \\
\text { Staff } \\
\text { (FTE) } \\
(\%)\end{array}$ \\
\hline 1 & 94 & $<1$ & 2 & 0.11 & 1620 & 3 & 55.2 & 3.08 \\
\hline 2 & 1144 & 2 & 34.9 & 1.88 & 4314 & 9 & 381.5 & 21.26 \\
\hline $3 b$ & 2635 & 5 & 123.6 & 6.67 & 5234 & 11 & 314 & 17.50 \\
\hline $3 a$ & 5981 & 12 & 673.1 & 36.32 & 8863 & 18 & 604.1 & 33.67 \\
\hline 4 & 11932 & 25 & 606.1 & 32.71 & 13257 & 28 & 247.6 & 13.80 \\
\hline 5 & 17260 & 36 & 413.3 & 22.30 & 9611 & 20 & 104.2 & 5.81 \\
\hline $5^{*}$ & 8975 & 19 & 0 & 0 & 5175 & 11 & 87.8 & 4.89 \\
\hline Total & 48022 & 100 & 1853 & 100 & 48072 & 100 & 1794.4 & 100 \\
\hline
\end{tabular}

\section{Australia: Present And Proposed Models}

Over three billion dollars are spent on research for Australian universities (Leeder, 2005). Geuna \& Martin (2003) summarise the current Australian model as a combination of an institutional operating grant with a separate, targeted grant scheme. There are three components to the targeted portion.

- $\quad$ Research Training Scheme (RTS): Funds are allocated based on 40\% research income, 50\% research student completions and $10 \%$ research publications.

- $\quad$ Research Infrastructure Block Grant (RIBG). These is wholly allocated on the relative success of each institution in obtaining research funds based on Australian competitive grants (in other words 100\% inputs focused measured as research income, with no percentage weightings to research student completions or publications outputs).

- $\quad$ Research Quantum. This was originally $100 \%$ based on past grant success record of a university, but due to criticisms was slightly widened (Guena and Martin, 2003). The current weightings are $60 \%$ research income, $30 \%$ research student load and 10\% research publications (RQF, 2005). 
Overall, the above criteria have two major flaws: the distorted allocation of input versus output measures and the focus on quantity and not quality. The percentage weightings of the three research schemes clearly disadvantages schools such as visual arts since it is primarily driven on past grant success. Those universities with medical schools and/or large science labs are likely to get the lion share of the funds. Another major criticism of the current Australian system is its rules-based mechanistic nature. Bourke (1997, p.25) argues the inadequate nature of such a system as it "is confined to counting annually the gross number of undifferentiated entrants each institution can place in the classification categories which are weighted for funding purposes." The focus is purely on the quantity of inputs (grants) and outputs (supervision completions and publications/exhibits. There is no focus on the quality of the contribution (outcomes).

Each year in Australian university rankings are made with the announcement of successful ARC granting rounds. While these rankings may be useful as marketing purposes these sorts of measures aren't necessarily transparent in what has been achieved nor do they drive quality improvement related behaviours. Additionally there is criticism at comparing different types of institutions, i.e. one with a medical school and one without (RQF, 2005).

The Australian federal government is likely to institute some form of research assessment exercise for universities. The Research Quality Framework: Assessing the quality and impact of research in Australia was released as an Issues paper in 2005. The Federal Minister for Education, Dr Brendan Nelson, stated "An RQF will provide a consistent and comprehensive approach to assessing publicly funded research. It will drive positive research behaviours, encouraging researchers and research organisation to focus on the quality and impact of their research. The Australian Government is committed to ensuring that resources provided to carry out research are directed to areas of research excellence and public benefit" (Minister's Foreword, 2005, p.1). An Expert Advisory Group for an RQF was established in 2004. The Chair is Sir Gareth Roberts, the individual that lead the 2003 review of the UK RAE and one of the panel members is Professor Paul Callaghan, Chair of Moderation Panel for the New Zealand Performance Based Research Fund. Therefore, as expected the Australian RQF theme is largely consistent with the earlier UK and NZ initiatives (Research Quality Framework, Advanced Approaches Paper, 2005). However, there are several controversial elements. Healy (2005a) argues that splitting universities as research-oriented or non-research oriented is false dichotomy. Yaman (2005, p.37) notes that the result may well be zero research funds for some. Healy, quoting James, argues that "The Federal Government's research agenda encouraged research in 'priority areas' that copied international headline trends, concentrated funding a few hands, emphasised science-oriented research and set up expectations of commercially-applicable research and dreams of generating wealth ...All of these ... have almost nothing to do with quality... Intellectual scientists of the last generation ...must be turning in their graves" (2005a, p. 13). Healy (2005b) notes the RQF paper reinforces the potentially widening division of academic labour. In a similar view the National Tertiary Education Union "has criticised the suggestion that the requirement be removed for potential university aspirants to engage in research and offer a broad range of disciplines, stating it would lower standards and reduce quality across the sector... and will merely reduce diversity and encourage institutions into destructive competition against each other on a narrow range of highly profitable disciplines" (The Australian, 2005b, p.13).

\section{THE WAY FORWARD}

Geuna and Martin (2001, p.26) state that "most of the countries examined have either recently implemented some form of performance-based allocation or are considering doing so in the near future." Overall, the international assessments of research share two common purposes, improving the quality/focus of research and enhancing accountability for public funding (RQF, 2005).

Geuna and Martin (2003) summarized changes taking place in several countries. Their major findings were that many countries are increasingly relying on self evaluation and a growing emphasis in many countries to linking research performance to the allocation of block funds to universities. They note there are problems with applying models developed for larger countries e.g. the UK to smaller countries. In many ways, the British RAE has served as the model for the world. However, it does have its critics. Lucas (2004) notes that there are concerns that it has created divisions within departments and the relegation of teaching as a secondary priority. 
In the 2003 review of the UK RAE five themes for the improvement of the assessment process emerged:

- $\quad$ The need for a clear link between assessment outcomes and funding

- The need for greater transparency, especially panel selection

- $\quad$ The need to ensure consistency of practice across assessment panels, including the trade-off between comparability of grades across subjects and the flexibility for assessors to develop methods appropriate to their subject

- $\quad$ The need for continuous rating scale

- $\quad$ The need for a properly resourced administration

Overall, there are important ongoing concerns with national research assessment schemes. Guena and Martin (2003) note it may encourage publication inflation (by splitting publications into the lowest possible units), game playing behaviour, and possibly most worrying to visual arts academics is that it may encourage a greater focus on 'traditional academic research' (ie publications) and discourage more adventurous and creative scholarship. The Australian Government is not planning to allocate new monies for the implementation of the RQF and there is no new money to provide assessment panels. There is thus an open question whether such a national assessment exercise will be yet another drain to administration of monies originally allocated for research? Consideration should be given to the less expensive continental European models such as that used in Holland that allow for the assessment of research quality in a framework that is more economically structured.

In summary, we find that whilst the current definition of research in Australia is broad enough to include most of the activities of visual arts academia. The actual operationalisation of the measurement models excludes many current activities. The need to clearly demonstrate quality peer review is the largest hurdle. This paper provides analyse of the likely introduction of a 'quality assessment exercise' in Australia based on the recent New Zealand and UK experiences (Tertiary Education Commission. 2004; RAE, 2001). Whilst visual arts academia research performance activity was ranked low in both countries (Table 3), we find that their move towards quality and peer assessment offers a potentially broader and more accurate depiction of activity. Obtaining a balanced broader assessment of both traditional research performance measures such as research publications along with the more creative elements of visual arts such as exhibitions is paramount. A 2004 National Academies Forum symposium stressed the need for diversity in research and felt that further work was needed to examine discipline specific and cross-disciplinary measures for research quality and impact. As noted by the RQF (2005, Section 1.4):

"One important lesson is the need to engage the support of the research community in undertaking research assessment. Another lesson related to the need to have clarity about the way in which the outcomes of research assessment will inform funding. Another lesson related to the need for research assessment exercise to be sufficiently flexible to accommodate the breadth of different fields of study. In particular, it is important that excellence in the humanities and social sciences can be compared with that of the physical sciences on a level playing field."

Thus, the RQF realises the importance of adopting a framework that allows disciplines such as visual arts a fair go. "The metrics should be able to be adjusted according to the particular shape of disciplines. For example, in the arts and humanities, it may be more relevant to include performances, exhibitions, and other esteem indicators, whereas in the sciences, more focus might be given to citations indices" (RQF, 2005, Section 2.3). Yet, the RQF itself follows the above noteworthy concepts with a key table listing a very narrow set of examples of possible metrics. The aim may well be worthy, but the devil may thus be in the details.

Yet, in regards to visual arts academia there may be some silver lining in the clouds. National research assessment exercises have several important advantages. We argue that universities are currently undercounting visual art performance because of problems documenting research activity. The implementation of a national research assessment exercise may assist the visual arts discipline by 1) providing an expert panel of peer reviewers that understand the value of performances and exhibitions, 2) provide a funding mechanism system that places far greater focus on research outputs (production) and a concurrent lesser focus on research grants. This is arguably much fairer for a social science discipline. 
The overall low research productivity levels in past national RAEs show that visual arts academics in Australia are struggling to compete with their academic brethren in other disciplines. We argue the need for the discipline to evolve an acceptable peer review system to better access their broad research activities is paramount. The implementation of a national research assessment system will engender this debate. A positive aspect of the RAE debate is greater recognition by visual arts academics of the crucial importance of communicating their research in both practice-based and scholarly-based venues. Finally, the visual art global business is crucially dependent on the creative and scholarly contributions of the visual art academic community. They communicate, highlight and create national treasures. A comprehensive, effective system to assess and reward visual art research output should greatly assist the business of art.

\section{ACKNOWLEDGMENTS}

The authors would like to thank Emily Go forth for her valuable assistance in the literature review, survey preparation and the data analysis for this project. The valuable feedback on an earlier draft of this work from the participants of the 2005 European Applied Business Research conference, Athens Teaching and Learning Conference, and Accountability Interest Group, Accounting and Finance Association of Australia and New Zealand is greatly appreciated.

\section{REFERENCES}

1. Bourke, P. (1997). Evaluating University Research: The British Research Assessment Exercise and Australian Practice, Commissioned Report No. 56, Canberra: National Board of Employment Education and Training.

2. Carnegie Foundation's Special Report entitled Scholarship Reconsidered, 1990.

3. Diamond, J. (1997). Guns, Germs and Steel: A History of Everybody for the last 13,000 Years, Vintage: London.

4. Geuna, A. and Martin, B.R. (2003). University Research evaluation and funding: An International Comparison, Minerva (41), 277-304.

5. Harnad, S., Carr, L., Brody, T., \& Oppenheim, C. (2003). Mandated Online RAE CVs Linked to University Eprint Archives: Enhancing UK Research Impact and Assessment, Ariadne, Issue 35, 1-16.

6. Healy, G. (2005a). RQF Offering Crumbs From the Rich Man's Table, Campus Review, 30 March 2005, p.1, 13.

7. Healy, G. (2005b). On a Sliding Scale: RQF Looks at Rankings and Ratings, Campus Review, 6 April, 2005, p.5.

8. Hills, P.V. and Dale, A.J. (1995). Research and Technology Evaluation in the United Kingdom, Research Evaluation, 5 (1), 35-44

9. Jones, L. (2004, March). Linking research and teaching: The significance of research funding and evaluation policies, Research and Teaching: Closing the Divide?, An International Colloquium, Winchester, England.

10. Kaukonen, E. (1997). Evaluation of Specific Research in Finland. In OECD (Ed.) The Evaluation of Scientific Research: Selected Experiences. Paris: OECD.

11. Leeder, S. (2005). Research for the Good of Everyone, The Australian, 6 April, 2005, p.32.

12. Lucas, L. (2004). Linking Research and Teaching: The significance of research funding and evaluation policies, Research and Teaching: Closing the Divide? An international colloquium, Marwell Conference Centre, Winchester, England, 18-19 March 2004.

13. McNeill, W. (1979). A World History, $3^{\text {rd }}$ edition, Oxford University Press: New York.

14. Minister's Foreword (2005). In RQF [Research Quality Framework], A Research Quality Framework: Issues Paper, Commonwealth of Australia: Canberra.

15. OECD (1987). Universities Under Scrutiny, OECD: Paris.

16. Plummer, K. (2005). University of Auckland. academic, Personal correspondence.

17. Ross, D. (2004). Scotland: History of a Nation, Lomark Books: New Lanark, Scotland.

18. RQF [Research Quality Framework] (2005). A Research Quality Framework: Issues Paper, Commonwealth of Australia: Canberra.

19. RQF [Research Quality Framework] (2005). Research Quality Framework: Assessing the Quality the Impact 
of Research in Australia: Advanced Approaches Paper, Commonwealth of Australia: Canberra.

20. The Australian (2005a). ANU and Sydney University Join Forces, 3 April, 2005, p.13.

21. The Australian (2005b). Discussion Paper on University Protocols, 3 April, 2005, p.13.

22. The Australian (2005c). New Research Priorities Standing Committee Appointed, 3 April, 2005, p.1.

23. University Grants Committee (UK) (2005). RAE Guidance Notes, University Grants Committee: Hong Kong.

24. Yaman, E. (2005), Zero Research Funds for Some, The Australian, 20 April, 2005, p.37.

25. Van der Zahn, M. (2005). Singapore Management University. academic, formerly an academic in Hong Kong, Personal correspondence.

26. Van Peursem, K. (2004). Waikato University. academic, Personal correspondence.

\section{WEB REFERENCES}

1. Department of Education, Science and Training, Research Quality Framework: Assessing the Quality and Impact of Research in Australia; Issues Paper, Accessed on April 10, 2005 from http://www.dest.gov.au/ resqual/documents/rqf_issuespaper.pdf

2. Foy-Smith, C., Who buys paintings for $\$ 104 m$ ?, Accessed April 18, 2005 from http://news.bbc.co.uk/2/ hi/uk_news/magazine/3689967.stm

3. Geuna, A. and Martin, B.R., University Research Evaluation and Funding: An International Comparison. Accessed on March 23, 2005 from http://www.sussex.ac.uk/spru/1-6-1-2-1.html

4. Guardian About the Tables, Accessed on April 14, 2005 from http://education.guardian.co.uk/ secondaryschoolsguide.story/0,11228,602663,00.html

5. Oxford English Dictionary, Oxford English Dictionary Online, Accessed April 4, 2005 from http://dictionary.oed.com.ezproxy.library.uwa.edu.au/entrance.dtl

6. Higher Education and Research Opportunities, Panels' Criteria and Working Methods, Accessed March 23, 2005 from www.hero.ac.uk/rae/criteria/crit64.htm

7. Higher Education and Research Opportunities, A Guide to the 2001 Research Assessment Exercise, Accessed on April 4, 2005 from http://195.194.167.103/Pubs/other/raeguide.pdf

8. Tertiary Education Commission, PBRF Definition of Research, Accessed on April 42005 from http://www.otago.ac.nz/research/pbrf/\#definition

9. Department of Education, Science and Training, Higher Education Research Data Collection: Specifications for the collection of 2004 Data, Accessed on April 4, 2005 from http://www.dest.gov.au/highered/ research/documents/specs2005.pdf

10. University Grants Committee, Appendix 1, Accessed on April 19, 2005 from http://www.ugc.edu.hk/eng/ ugc/publication/prog/rae/appenda.htm

11. University Grants Committee, Research Assessment Exercise 2006

12. Information Note, Accessed on April 13, 2005 from http://www.ugc.edu.hk/eng/doc/ugc/publication/ prog/rae/rae2006.pdf

\section{APPENDIX A: CARNEGIE (1990) DEFINITION OF SCHOLARSHIP}

While scholarship means engaging in original research, scholarship now has a broader and capacious meaning. Beyond the age-old "teaching Vs research" debate, there are four separate, yet overlapping functions: they are the scholarship of discovery; the scholarship of integration; the scholarship of application; and the scholarship of teaching.

\section{Scholarship Of Discovery}

The scholarship of discovery, at its best, contributes not only to the stock of human knowledge but also to the intellectual climate of an institution. It is a scholarly investigation, closest to what is meant when academics speak of "research", that confronts the unknown and creates new knowledge. Not just the outcomes, but the process, and especially the passion, give meaning to the effort. 


\section{Scholarship Of Integration}

It is a serious, disciplined work that seeks to interpret, draw together and bring new insight to bear on original research. The scholarship is closely related to discovery. Such work is increasingly important as traditional disciplinary categories prove confining, forcing new topologies of knowledge. This scholarship also means interpretation, fitting one's own research -- or the research of others -- into larger intellectual patterns. A variety of scholarly trends -- interdisciplinary, interpretive, integrative, are examples of scholarship of integration.

\section{Scholarship Of Application}

It is a dynamic process of creating new intellectual understandings arising out of theory and practice. The term itself may be misleading if it suggests that knowledge is first "discovered" and then "applied". The process is in fact more dynamic; new intellectual understanding can arise out of vital interaction between theory and practice, and one renews the other.

\section{Scholarship Of Teaching} to the learners.

It is a process that transforms and extends knowledge while transmitting an intelligible account of knowledge

\section{NOTES}

